Article

\title{
Ethyl Methyl Sulfonate-Induced Mutagenesis and Its Effects on Peanut Agronomic, Yield and Quality Traits
}

\author{
Tingting Chen ${ }^{1}$, Luping Huang ${ }^{1}$, Miaomiao Wang ${ }^{1}$, Yang Huang ${ }^{1}$, Ruier Zeng ${ }^{1}$, Xinyue Wang ${ }^{1}$, \\ Leidi Wang ${ }^{1}\left(\mathbb{D}\right.$, Shubo Wan ${ }^{2, *}$ and Lei Zhang ${ }^{1, * \mathbb{C}}$ \\ 1 Guangdong Key Laboratory of Plant Molecular Breeding, State Key Laboratory for Conservation and \\ Utilization of Subtropical Agro-Bioresources, South China Agricultural University, Guangzhou 510642, \\ China; chentingting@scau.edu.cn (T.C.); lupinghuang2019@163.com (L.H.); 15802020854@163.com (M.W.); \\ hy1294276320@163.com (Y.H.); ruierzeng@126.com (R.Z.); wangxinyuescau@163.com (X.W.); \\ wangld@mail.iap.ac.cn (L.W.) \\ 2 Biotechnology Research Center, Shandong Academy of Agricultural Science, Jinan 250100, China \\ * Correspondence: wanshubo2016@163.com (S.W.); zhanglei@scau.edu.cn (L.Z.)
}

Received: 2 April 2020; Accepted: 30 April 2020; Published: 5 May 2020

\begin{abstract}
Peanut is an important oilseed and food crop worldwide; however, the development of new cultivars is limited by its remarkably low genetic variability. Therefore, in order to enhance peanut genetic variability, here, we treated two widely cultivated peanut genotypes, Huayu 22 and Yueyou 45, with different concentrations of the mutagen ethyl methyl sulfonate (EMS) for different durations. Based on median lethal dose (LD50) value, optimal EMS treatment concentrations for each duration were identified for each genotype. Mutants induced by EMS differed in various phenotypic traits, including plant height, number of branches, leaf characteristics, and yield and quality in plants of the M2 generation. Moreover, we identified potentially useful mutants associated with dwarfism, leaf color and shape, high oil and/or protein content, seed size and testa color, among individuals of the M2 generation. Mutations were stably inherited in M3-generation individuals. In addition to their contribution to the study and elucidation of the mechanisms underlying the regulation of the expression of some important agronomic traits, the mutants obtained in this study provide valuable germplasm resources for use in peanut improvement programs.
\end{abstract}

Keywords: Arachis hypogaea L.; EMS; mutant; dwarf; high protein; breeding

\section{Introduction}

Peanut (Arachis hypogaea L.) is one of the most important oil and protein crops in the world. In 2017, global peanut production reached $47.10 \mathrm{M}$ tons in a total cultivated area of $27.95 \mathrm{M}$ ha [1]. As peanut demand continues to increase, there is an urgent need to breed new peanut varieties with high yield and quality, in addition to resistance to biotic and abiotic stress factors [2]. However, cultivated peanut is an allotetraploid species that shows very low genetic variability through artificial selection over many decades [3]. Furthermore, peanut crop improvement should start with the formation of new germplasm that may then be used as source of highly desirable, outstanding performance traits.

Induced mutagenesis is one of the most important approaches for broadening crop genetic variability to overcome the limitations associated with a narrow genetic basis [4]. Induced mutants not only serve as an important functional genomics tool, but additionally, as intermediate material in crop breeding [5-8]. Thus, induced mutagenesis have also been used in peanut [9-11] to generate mutants for high-oleate content [12-15], color of the testa [16], photosynthetic activity [17], salinity resistance [18] and resistance to biotic stress [19], and pod development [20]. Among available mutagens, ethyl methyl sulfonate (EMS) is a potent and popular chemical mutagen that has been 
effectively used to induce a high-density of random irreversible point mutations uniformly distributed in the genome [21,22]. The EMS induces single nucleotide changes by alkylation of specific nucleotides, resulting in a high frequency of single nucleotide polymorphisms (SNPs) and insertion/deletions (InDels) in the genic sequences and coding sequence (CDS) region, which is considered as an excellent resource for targeting induced local lesions in genomes (TILLING) [23,24]. However, few studies have reported a mutant peanut variety library constructed by an optimal EMS treatment, because mutagenic efficiency depends on many different factors including, EMS concentration, treatment duration, peanut genotype, temperature, etc., $[25,26]$. To further improve the mutagenesis protocol for peanut, in this study, two different peanut genotypes were treated with different EMS concentrations for different time periods to optimize EMS treatment and identify stably-inherited mutations to improve peanut varieties.

\section{Materials and Methods}

\subsection{Plant Materials}

Two different A. hypogaea cultivars, namely, 'Huayu 22' (HY22) and 'Yueyou 45' (YY45), from North and South China, respectively, were used in this study. HY22 belongs to the common larger-sized kernel varieties with high quality and yield potential [27]. On the other hand, YY45 belongs to the Spanish type of peanut with smaller-sized kernels with high resistance to rust, leaf spot and bacterial wilt [28], used predominantly for peanut candy, salted peanuts, and peanut butter.

\subsection{EMS Treatment}

Sixteen treatments were tested at $25^{\circ} \mathrm{C}$, which consisted of four EMS (Sigma, St Louis, USA) concentrations $(0.3 \%, 0.6 \%, 0.9 \%$ and $1.2 \%)$, each combined with four treatment duration times $(1,3,5$, and $7 \mathrm{~h}$ ). Seeds soaked in $0.1 \mathrm{M}$ phosphate buffer ( $\mathrm{pH}$ 7.0) were used as the control treatment. Fifty seeds of each, HY22 and YY45, were subjected to each combination treatment and the control treatment. There are two replications for each treatment. Treated and control seeds were then thoroughly washed under running water for $3 \mathrm{~h}$ and transferred to pots filling wet sand and placed in an incubator for germination at $25^{\circ} \mathrm{C}$ in the dark until radical emergence $[29,30]$.

\subsection{Generating Mutant Populations}

All germinated and non-germinated seeds were sown in the field. The size of individual plots was $1.6 \times 1.6 \mathrm{~m}$. Planting distance between and within rows was $20 \mathrm{~cm}$. Standard cultural practices were carried out thereafter. The experiment was laid in a complete randomized-block design at the Experimental Station of South China Agricultural University in Guangzhou ( $\left.23^{\circ} 5^{\prime} \mathrm{N}, 113^{\circ} 23^{\prime} \mathrm{E}\right)$, Guangdong, China. M1 plants were self-pollinated to create M2 families. M2 seeds were harvested from 349 and 374 surviving M1 plants of HY22 and YY45, respectively. In the spring of 2019, 20 seeds from each M2 family were planted to grow an M3 generation, again, in a complete randomized-block design.

\subsection{Phenotype}

Mutants were detected by visual observation of the plants during the whole plant growing cycle in each generation. Visual phenotypic variation in growth performance and leaf morphology were recorded and photographs were taken to document the comparison between mutants and their control. After harvest, plant height, number of branches and total pod number per mutant or control were recorded. Pods were harvested from the parent plants and then dried. Total pod number (TPN) per plant was counted. The weight of twenty full pods of each plant was determined. After removal of pod shells, the weight of twenty full seeds sampled from each plant was determined. The 100-pod weight (HPW) and 100-kernel weight (HKW) were calculated as five times the weight of twenty full pods and twenty full seeds, respectively. Oil and protein from clean seeds were measured using a near-infrared reflectance (NIR) analyzer (DA 7250, Perten Instruments, Inc., Springfield, IL, United States) by the methods reported previously [31]. 


\subsection{Statistical Analysis}

All obtained data from the M1 generations were subjected to analysis of variance (ANOVA) using SPSS 16.0 software (SPSS, Chicago, IL, USA). The analyzed data were presented as means $( \pm \mathrm{SD})$ of two replicates.

\section{Results}

\subsection{Germination Rate and LD50 in the M1 Generation}

Field germination rates of HY22 and YY45 in generation M1 were surveyed at $10 \mathrm{~d}$ after sowing. Figure 1 showed that there were 8 and 10 lethal treatments for HY22 (0.6\% EMS for 5 or $7 \mathrm{~h}, 0.9 \%$ for 3 , 5 , or $7 \mathrm{~h}$, and $1.2 \%$ EMS for 3, 5, or $7 \mathrm{~h}$ ) and YY45 ( $0.6 \%$ and $0.9 \%$ EMS for 3, 5, or $7 \mathrm{~h}$, and $1.2 \%$ for 1,3 , 5 , or $7 \mathrm{~h}$ ), respectively. Except those lethal treatments, the germination rates of the other EMS-treated seeds of both genotypes were significantly $(p<0.05)$ reduced by EMS treatment, except $0.3 \%$ EMS for 1 $\mathrm{h}$ in $\mathrm{YY} 45$, compared to the corresponding control (i.e., 79\% for HY22 and $87 \%$ for $Y Y 45$ ) (Figure 1). Moreover, under the same EMS concentration, different changes of germination rates were observed in different durations of both genotypes. In HY22, for $0.3 \%$ EMS concentration, no significant difference was found among durations of 1,3,5 h or 5, $7 \mathrm{~h}$. However, significant difference was showed between 1,3 , and $7 \mathrm{~h}$. For $0.6 \%$ EMS concentration, there was no significant difference between $1 \mathrm{~h}$ and $3 \mathrm{~h}$. In YY45, for 0.3\% EMS concentration, no significant difference was found between the durations of 1, $3 \mathrm{~h}$ and 5, $7 \mathrm{~h}$. However, significant differences were showed between 1 and $5 \mathrm{~h}, 1$ and $7 \mathrm{~h}, 3$ and $5 \mathrm{~h}$, and 3 and $7 \mathrm{~h}$. In addition, the germination rates of EMS-treated YY45 seeds were higher than those of HY22 under $0.3 \%$ EMS for $1,3,5$, or $7 \mathrm{~h}$, and under $0.6 \%$ EMS for $1 \mathrm{~h}$.
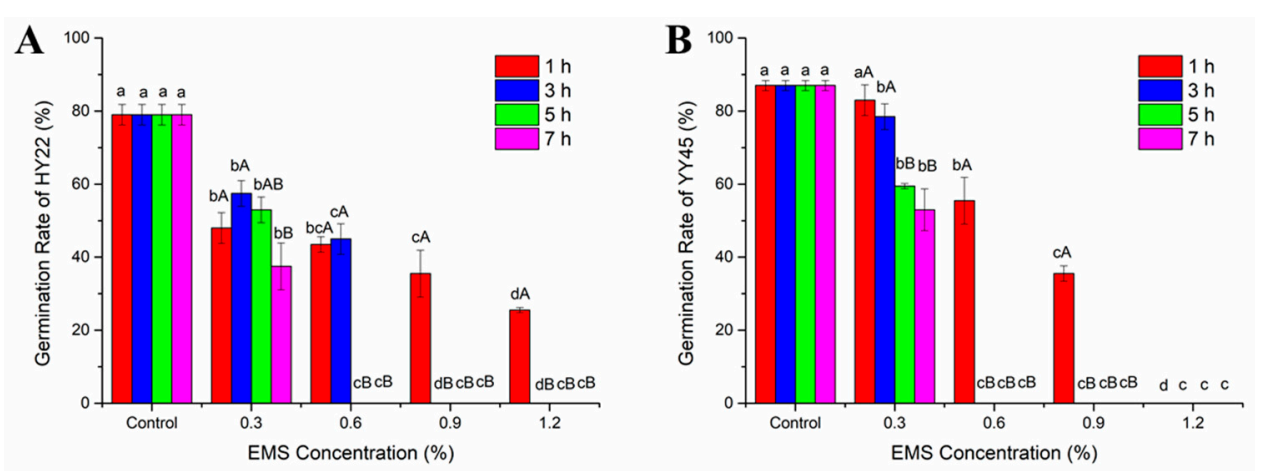

Figure 1. The germination rate of M1 generation HY22 and YY45 induced by different ethyl methyl sulfonate (EMS) treatments. (A) Germination rate of 'Huayu 22' (HY22) induced by different EMS treatment; (B) Germination rate of 'Yueyou 45' (YY45) induced by different EMS treatment. Note: Mean values within different EMS concentration followed by lower cases are significantly different at $p<0.05$. Mean values within different duration followed by upper cases are significantly different at $p<0.05$.

The median lethal dose (LD50) is usually used as a critical parameter for chemically induced mutagenesis. The LD50 values for mutagenesis of peanut with different EMS concentrations for each duration were estimated through linear regression based on lethal rate (Figure 2). Based on the lethal rate of HY22, LD50 values were calculated $0.51 \%, 1.41 \%, 0.27 \%$ and $0.19 \%$ for durations of $1,3,5$ and $7 \mathrm{~h}$, respectively. For YY45, LD50 values were estimated $0.63 \%, 0.40 \%, 0.33 \%$ and $0.31 \%$ for durations of 1, 3, 5 and $7 \mathrm{~h}$, respectively (Figure 2, Supplementary Table S1). The data showed that the LD50 of HY22 were lower than those of YY45 for 1, 5 and $7 \mathrm{~h}$, whereas it is converse for $3 \mathrm{~h}$. 


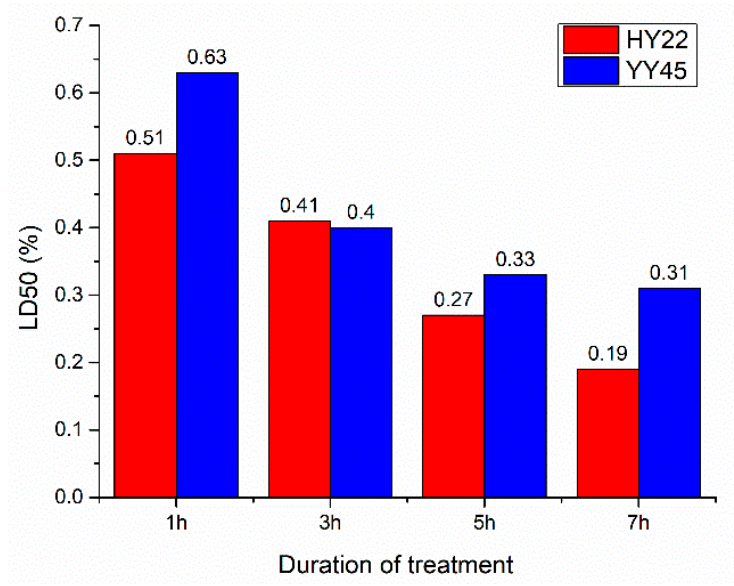

Figure 2. Median lethal dose (LD50) values of HY22 and YY45 with different EMS treatments.

\subsection{Plant Height and Branch Number in Population M2}

In order to analyze the agronomic traits in peanut, plant height and number of branches were recorded after harvest. For plant height, the peak of frequency (number of M2 families) in M2 populations of HY22 and YY45, were $25.49 \%$ (78) and $31.77 \%$ (115) at the groups of $40-44.99 \mathrm{~cm}$ and 35-39.99 cm, while the average value among HY22 and YY45 control plants was 43.4 and $38.5 \mathrm{~cm}$, respectively. In M2 populations of HY22, the groups of 0-39.99 cm and 45-89.99 cm accounted for $27.78 \%$ (85) and $46.73 \%$ (143), respectively. As for YY45, the groups of $0-34.99 \mathrm{~cm}$ and $40-89.99 \mathrm{~cm}$ accounted for $24.03 \%$ (87) and $44.20 \%$ (160), respectively (Figure 3A).
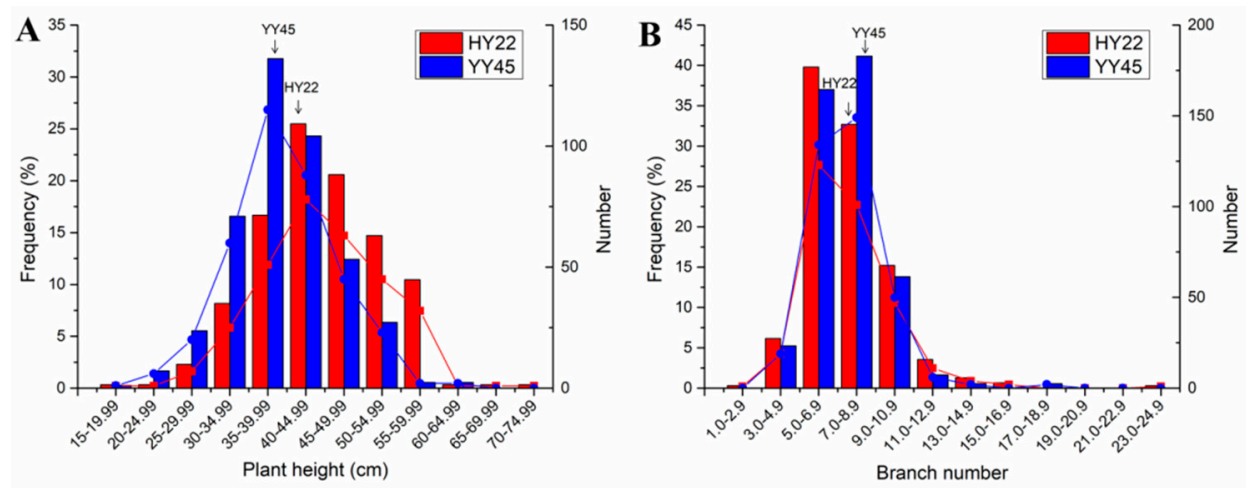

Figure 3. Frequency and number distribution of agronomic traits of M2 generation of HY22 and YY45 induced by EMS treatments. (A) Plant height; (B) Number of branches.

For the number of branches, the average of number of branches in HY22 and YY45 plants were 8.5 and 7.4, respectively (Figure 3B). The peak of frequency (number of M2 families) in M2 populations of HY22 and YY45, were $39.80 \%$ (123) and $41.16 \%$ (149) at the groups of 5.0-6.9 and 7.0-8.9. Except for groups including the control plants, there were $46.28 \%$ (143) families in the less-branches group and $21.04 \%$ (65) families in the more-branches group among HY22 plants in the M2 generation, whereas $42.26 \%$ (152) less-branches families and 16.57\% (60) more-branches families were observed among YY45 plants of the same generation.

\subsection{Plant Yield in the M2 Generation}

In order to explore the effect of EMS treatment on yield, total pod number (TPN), hundred-pod weight (HPW) and hundred-kernel weight (HKW) per plant were studied in generation M2.

For TPN per plant, the peaks both appeared at the group of 10.0-14.9. TPN of $85.16 \%$ (264) of HY22 families were decreased, compared to the control (TPN: 24.9). Only 4.52\% (14) of families were 
increased (Figure 4A). TPN in 45 YY45 M2 families was lower than that in the control (TPN: 11.4), accounting for $12.43 \%$. TPN in 168 YY $45 \mathrm{M} 2$ families was higher than that in the control, accounting for $46.41 \%$ (Figure $4 \mathrm{~A}$ ).
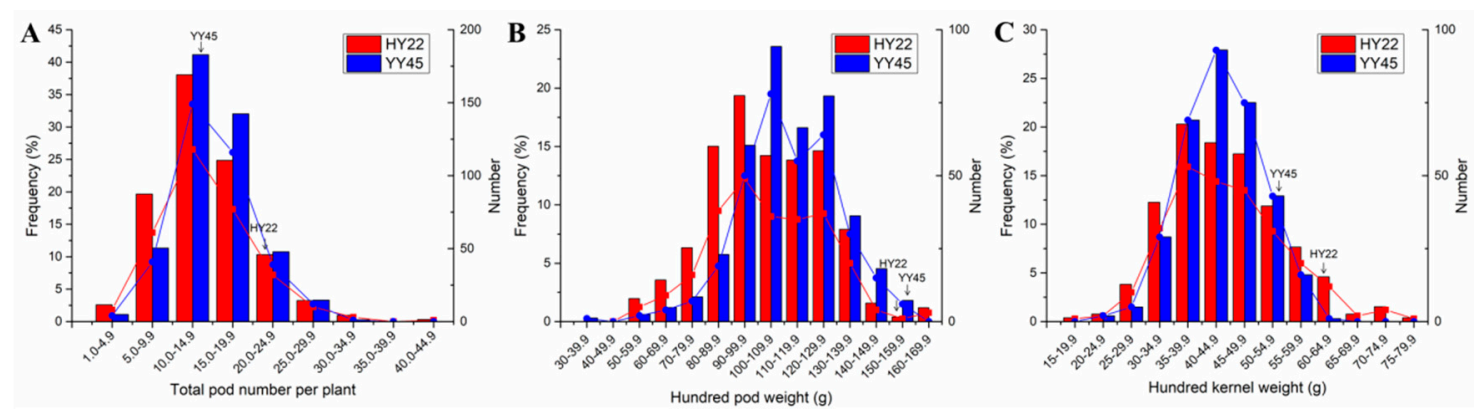

Figure 4. Frequency and number distribution of yield traits of M2 generation of HY22 and YY45 induced by EMS treatments. (A) Total pod number per plant; (B) Hundred pod weight; (C) Hundred kernel weight.

For HPW per plant, we observed the peak at the groups of 90-99.9 $\mathrm{g}$ and 100-109.99 $\mathrm{g}$ among the M2 generation of HY22 and YY45, whereas HPW of HY22 and YY45 control plants were 159 and $156 \mathrm{~g}$, respectively. In the mutant populations of HY22 and YY45, HPW of 249 and 325 families, respectively, decreased compared to the corresponding control, and accounted for $98.42 \%$ and $98.19 \%$, of the corresponding values, respectively. The data showed that HFW in M2 families of the two genotypes decreased relative to the corresponding WT (Figure 4B). For HKW per plant, the peaks of HY22 and YY45 appeared at the groups of 35-39.9 $\mathrm{g}$ and $40-44.9 \mathrm{~g}$, which were lower than mean value in HY22 control plants $(61 \mathrm{~g})$ and YY45 (54 g). Similarly, in mutant populations of HY22 and YY45, HKW of 242 and 273 families, respectively, decreased compared to the corresponding control, and accounted for $92.72 \%$ and $81.98 \%$, of the corresponding values, respectively (Figure $4 \mathrm{C}$ ). Thus, it was verified that HKW in M2 families of the two genotypes decreased compared to the corresponding control.

\subsection{Seed Quality in Plants of Generation M2}

Data in Figure 5A show that the peak of oil content (OC) at the group of 50-51.99 in the M2 population of HY22, accounting for $29.27 \%$, was lower than the HY22 control plants (mean OC: $55.57 \%$ ). Compared with the control, low and high OC were observed in 256 (89.20) and 11 (3.81\%) M2 families, respectively. In the M2 population of YY45, the peak appeared at the group of 48-49.99, accounting for $32.54 \%$, which was lower than the control plants (mean OC: $51.16 \%)$. On the other hand, $237(70.12 \%)$ and $44(13.02 \%)$ M2 families had low and high OC compared to the control YY45 (Figure 5A). The data showed that OC in the mutant population of the two genotypes were decreased compared to their corresponding control.

It was found that the peak of protein content (PC) appeared at the group of 24-24.99 and 25-25.99 in the M2 population of HY22 and YY45, whereas PC of their control plants was $23.1 \%$ and $23.5 \%$, respectively. In total, 164 and 65 families of HY22 had higher and lower PC than the control, accounting for $57.14 \%$ and $22.65 \%$, respectively. Meanwhile, high PC was observed in 244 (73.05) M2 families of YY45, while lower PC was observed in 41 (12.28\%) families (Figure 5B). 

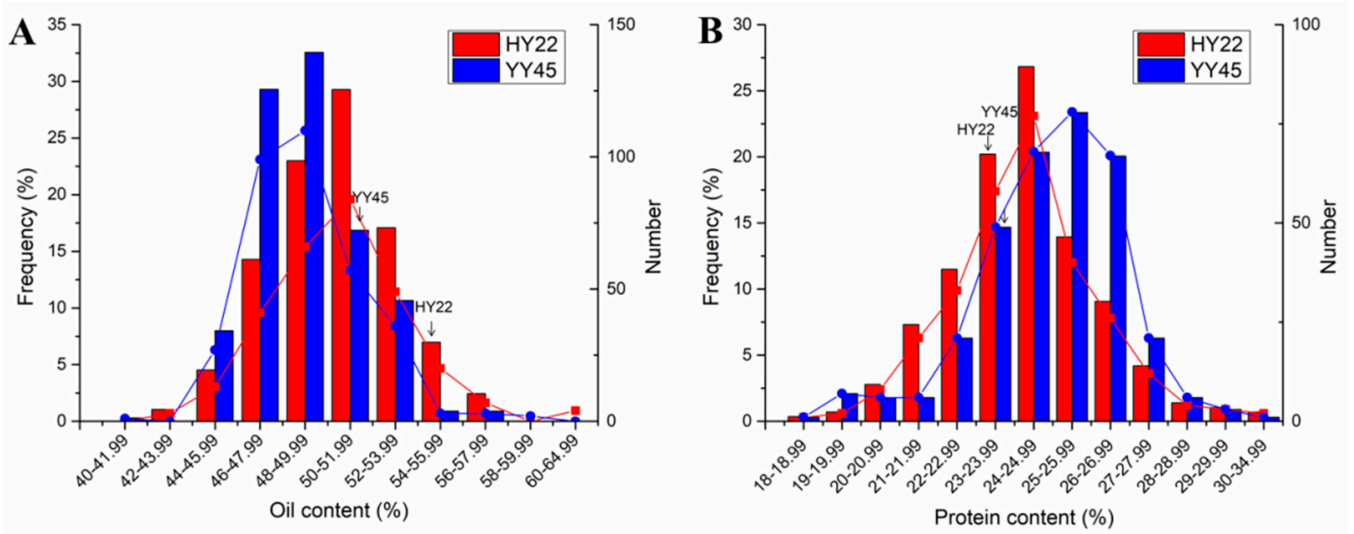

Figure 5. Frequency distribution of seed quality of M2 generation of HY22 and YY45 induced by EMS treatments. (A) Oil content; (B) Protein content.

\subsection{Mutants}

We identified several important mutations in the M2 generation that were stably inherited to the M3 generation. These included dwarfism, leaf color and shape, high oil and/or protein, seed size, and color of testa mutants.

\subsubsection{Dwarf Mutants}

Two mutants, HY-53 and HY-67, were dwarfs with height of 22.9 and $35.0 \mathrm{~cm}$, and smaller leaves than those of the control. These traits were stably inherited in the M3 generation (Figure 6A,B). Mutant YY-18 was a dwarf with height of $21.0 \mathrm{~cm}$, smaller and darker-green leaves than control YY45 (Figure 6C).

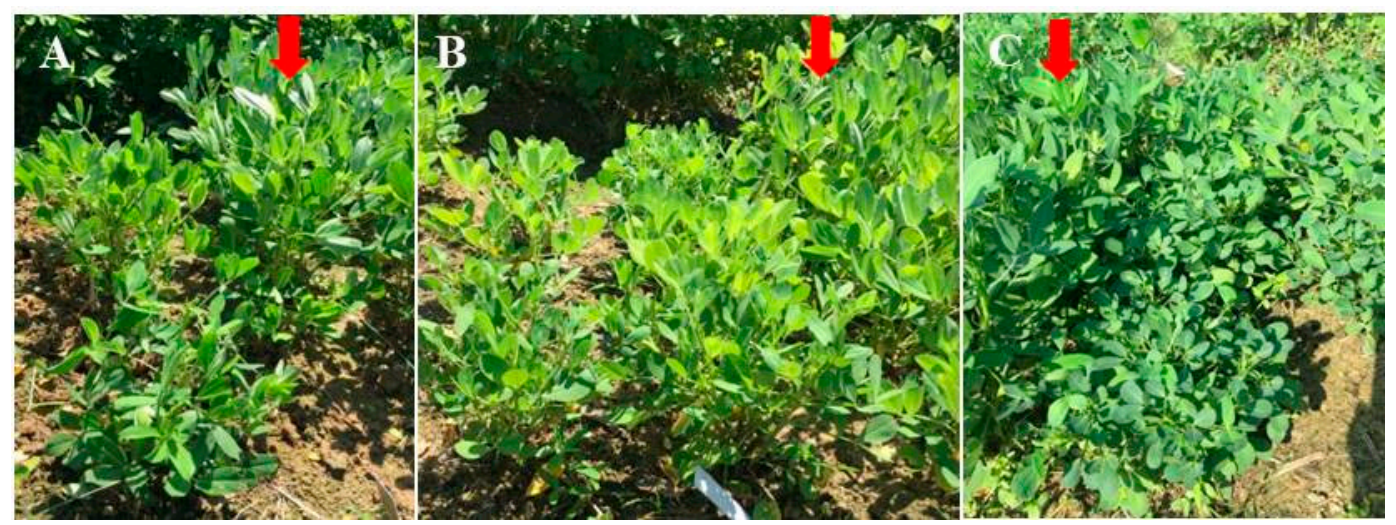

Figure 6. Mutants with dwarf and small-size leaves of HY22 and YY45. (A and B) Mutants of HY22;

(C) Mutants of YY45. Red arrows indicate the corresponding control.

\subsubsection{Leaf Color and Shape Mutants}

We found nine leaf-shape mutants among HY22 plants of the M2 generation, including two large-leaf, four small-leaf, and two slender-leaf mutants and one wrinkled-leaf mutant. There were 13 leaf-color mutants: yellow (Figure 7A), dark-green, and pale-green (Figure 7B) observed in five, four, and one mutant, respectively; one more mutant had the leaves with a chlorine-like color in the veins (Figure 7C), while two more mutants showed mosaic leaves (Figure 7D,E).

There were five leaf-shape mutants in YY45 plants of the M2, including four small-leaf mutants and one rolled-leaf mutants. Additionally, we found nine leaf-color mutants; one yellow-leaf, three dark-green-leaf and one pale-green-leaf mutant (Figure 7F); lastly, there were four rolled-leaf mutants (Figure 7G). 


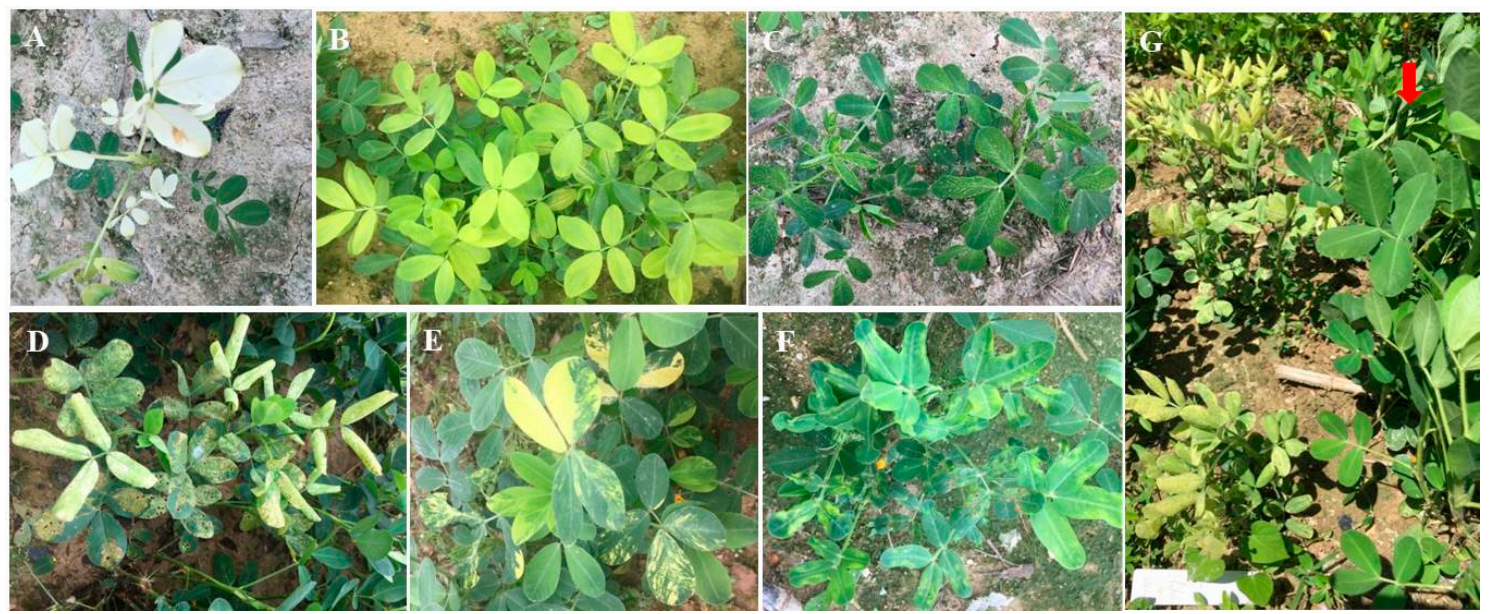

Figure 7. Mutants of leaf color of HY22 and YY45. (A-E) Mutants of yellow, pale green, veinal chlorine and mosaic leaves of HY22; (F,G) Mutants of mosaic and pale green leaves of YY45. Red arrow indicates the corresponding control.

\subsubsection{High oil and/or Protein Mutants}

Table 1 showed there were one high-oil dwarf mutant, six high-protein dwarf mutants, and one high-protein yellow-leaf mutant among HY22 individuals in population M2. On the other hand, we observed one high-oil, small-leaf mutant, two high-oil, high-protein, dwarf mutants, two high-protein dwarf mutants, and one high-protein large-leaf mutant among YY45 plants in population M2.

Table 1. Mutants related to high oil and/or protein of HY22 and YY45 induced by EMS treatment.

\begin{tabular}{|c|c|c|c|c|c|c|}
\hline & \multirow{2}{*}{$\begin{array}{c}\text { Mutant ID } \\
\text { HY93 }\end{array}$} & \multicolumn{2}{|c|}{ Phenotype } & \multirow{2}{*}{$\begin{array}{c}\begin{array}{c}\text { Oil Content } \\
(\%)\end{array} \\
64.58\end{array}$} & \multirow{2}{*}{$\begin{array}{c}\begin{array}{c}\text { Protein } \\
\text { Content }(\%)\end{array} \\
23.67\end{array}$} & \multirow{2}{*}{$\begin{array}{c}\begin{array}{c}\text { Plant } \\
\text { Height }(\mathbf{c m})\end{array} \\
30.6\end{array}$} \\
\hline \multirow{8}{*}{$\begin{array}{c}\text { HY22 } \\
\text { mutants }\end{array}$} & & High oil & Dwarf & & & \\
\hline & HY100 & High protein & Dwarf & 51.82 & 32.95 & 34.2 \\
\hline & HY104 & High protein & Dwarf & 40.33 & 30.06 & 36.7 \\
\hline & HY106 & High protein & Dwarf & 44.68 & 31.77 & 37.1 \\
\hline & HY123 & High protein & Dwarf & 44.96 & 32.03 & 30.3 \\
\hline & HY125 & High protein & Dwarf & 50.20 & 32.40 & 34.3 \\
\hline & HY126 & High protein & Dwarf & 47.06 & 32.13 & 35.0 \\
\hline & HY131 & High protein & Yellow leaves & 45.01 & 30.72 & 40.2 \\
\hline \multirow{6}{*}{$\begin{array}{c}\text { YY45 } \\
\text { mutants }\end{array}$} & YY37 & High oil & Small leaves & 59.70 & 21.06 & 45.0 \\
\hline & YY38 & High oil and protein & Dwarf & 61.93 & 32.42 & 32.0 \\
\hline & YY47 & High oil and protein & Dwarf & 61.17 & 30.12 & 25.6 \\
\hline & YY62 & High protein & Dwarf & 44.86 & 30.66 & 34.8 \\
\hline & YY64 & High protein & Dwarf & 51.79 & 30.07 & 27.0 \\
\hline & YY66 & High protein & Big leaves & 45.74 & 30.54 & 41.9 \\
\hline
\end{tabular}

\subsubsection{Seed Size and Testa Color Mutants}

The mutant in Figure 8B is shorter than the HY22 control (Figure 8A). The seed testa in the mutant in Figure $8 \mathrm{C}$ became wrinkled and its red color more intense than that of the control. Cracks were observed on the testa of the mutant in Figure 8E compared to the YY45 control (Figure 8D). 


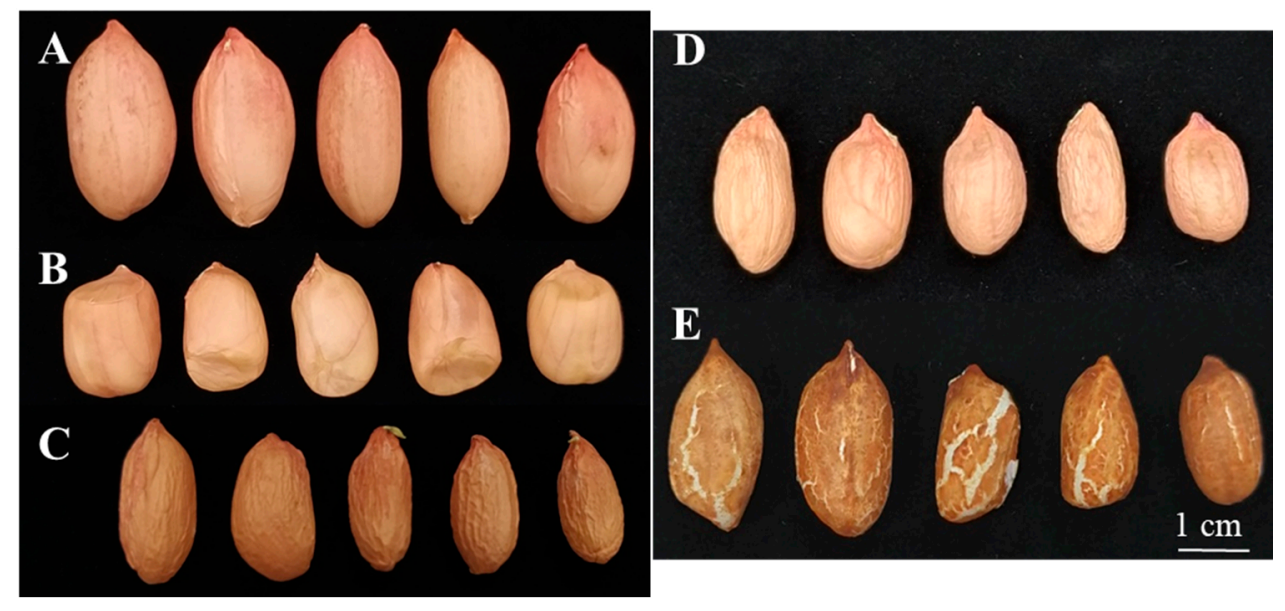

Figure 8. Seeds of mutants and their corresponding control. (A) The control HY22; (B,C) Mutants of HY22; (D) The control YY45; (E) Mutants of YY45.

\section{Discussion}

\subsection{Optimal Treatment Conditions Based on LD50}

Highly efficient mutagenesis is essential in mutagenesis-based breeding programs. Successful EMS-mediated mutagenesis depends on many factors, such as EMS concentration, treatment duration, and temperature, and others [4,32-34]. In the previous studies, several peanut genotypes, including Silihong, Baisha 1016 and Jinhua 8, were treated with different conditions. Then, researchers simply selected as optimal EMS treatment conditions closest to $50 \%$ of germination rate. However, few researchers have reported an analysis to determine proper EMS treatment conditions through linear regression for different peanut genotypes. In order to optimize EMS treatment conditions reasonably and correctly, here, we compared sixteen different treatments comprising four EMS concentrations and four treatment durations on two different peanut genotypes, HY22 and YY45. LD50 value for each duration was calculated based on lethal rate, which is as the optimal treatment conditions for each of the two genotypes studied.

Our results showed that EMS LD50 values for 1, 5 and $7 \mathrm{~h}$ in YY45 were higher than those in HY22, suggesting that the former is more resistant to EMS than the latter. Similarly, previous studies reported that sensitivity to chemical mutagens differs with genotype [35,36]. In addition, our results showed that 100-pod weight and 100-kernel weight decreased in the M2 population of both genotypes, as compared to the corresponding control. We inferred that this may be attributed to different physiological and biological processes related to yield, including enzyme activity and hormonal balance $[37,38]$. Furthermore, the toxic nature of the mutagen may reportedly damage cell constituents at the molecular level or alter enzyme activity $[39,40]$.

In previous research, it is verified that polyploid species are tolerant to high densities of induced mutations compared to diploids [41], which supports the hypothesis that loss-of-function mutations in polyploids are masked by genetic redundancy among homoeologs [42]. Such redundancy reduces the probability of selection of favorable mutations induced by EMS [43], mainly producing point mutations ( $G$ to $A$ and $C$ to $T$ ) in many crop species [44]. Peanut (AABB) is a tetraploid crop with very similar A and B sub-genomes, which frequenctly have more than $98 \%$ DNA identify between corresponding genes [43]. In this study, we inferred that many potentially useful induced mutants were likely masked by functional redundancy among homeologs in the mutant population of both genotypes. TILLING (targeting induced local lesions in genome) approach provides a relatively simple strategy to identify mutants in a target sequence independently of its phenotypic effect [45]. Combined with the exome capture technique, which is a smaller, specific portion of a plant genome that can be captured for resequencing [46], the protein coding regions could be captured to discover SNPs [47] and catalog 
induced mutations $[8,48]$. These mutations can be combined to study gene function and to reveal previously hidden phenotypic variation [42].

\subsection{Potentially Useful Mutants Associated Important Traits}

Dwarf and chlorotic mutants are the most readily visible, usual mutant types. Dwarf mutants in peanut can provide useful insights for understanding the regulatory mechanisms of plant growth and development, whereby they can be of great assistance in breeding programs. In our study, several dwarf mutants were observed. Previous studies suggested that dwarfism might be due to abnormal biosynthesis of indole acetic acid (IAA), gibberellin (GA), brassinosteroid (BR) or strigolactones (SL) [49-55]. For example, the tryptophan-deficient dwarf1 ( $t d d 1$ ) rice mutant, which is embryonic-lethal because of a failure to develop most organs during embryogenesis, is caused by TDD1, which encodes a protein that functions upstream of Trp-dependent IAA biosynthesis [52]. Similarly, a rice GA-insensitive dwarf mutant showed a severe dwarf phenotype containing high concentrations of endogenous GA [56]. Furthermore, the Arabidopsis dwarf mutant, shrink1-D (shk1-D), is produced by the activation of the CYP72C1 gene, which is a member of the cytochrome P450 monooxygenase gene family that regulates BR inactivation [57]. In turn, dwarf mutant dwarf11 (d11) rice bearing seeds of reduced length are controlled by the D11 gene encoding a novel cytochrome P450 (CYP724B1), which showed homology to enzymes involved in BR biosynthesis [58]. Lastly, mutant dwarf 53 (d53) rice controlled by the D53 gene encoding a substrate of the SCFD3 ubiquitination complex that functions as a repressor of SL signaling [59].

Several types of chlorosis, such as yellow, pale-green and vein-chlorosis, were identified in this study. In agreement with our results, previous studies found that a significant change in chlorophyll development always resulted in the variation of leaf color [60-63]. For example, chlorotic mutants defective in $\mathrm{ChlH}$, ChlD or ChlI encoding the Mg-chelatase subunits have been identified in Arabidopsis, rice, barley, and tea [64-68]. The loss of chlorophyll resulted from either a reduction or an excess accumulation of ChII [69]. In addition to genes encoding Mg-chelatase, other genes related to chlorotic leaves have also been identified, which influence the biosynthesis of chlorophyll and alter chlorophyll content. Firstly, OsYGL1, encoding a chlorophyll synthase responsible for catalyzing the esterification of chlorophyllide, was identified from a rice yellow-green leaf1 mutant that showed yellow-green leaves in young plants with reduced Chl synthesis, increased level of tetrapyrrole intermediates, and delayed chloroplast development [70]. Secondly, the ylc1 mutant showed reduced levels of $\mathrm{Chl}$ and lutein in young leaves compared to those of the control and turned green gradually, approaching normal green at maximum tillering stage, which was controlled by the chloroplast-localized gene, OsYLC1, whose protein is involved in Chl and lutein accumulation and chloroplast development during early leaf development in rice [71]. Similarly, in this study, the Chl-deficient mutant in Figure 7A showed completely etiolated newly grown leaves, light-green on middle leaves and regular green on the bottom part at seedling stage, a pattern that warrants further study.

Three more mutant types associated with seed quality, including high-protein/dwarf, high-oil/dwarf, and high-oil/large-leaf mutant, were observed in our study (Table 1). A previous study showed that gene FAD2 regulated high oleic-acid synthesis in peanut $[14,72,73]$. However, to date, only a few studies related to peanut seed-protein content have been reported. Mutations conferring different phenotypic variations are important for the functional analysis of corresponding genes; in addition, they offer an alternative plant material that peanut breeding programs can work with towards crop improvement for desirable traits. Therefore, in our future work, novel phenotypes resulting in phenotypic variation could be characterized using a combination of whole-genome resequencing, linkage maps and RNA-seq, providing a comprehensive picture of gene expression changes and newly introduced SNPs compared to wild-type, based on the reference genome of peanut. Once the gene function was identified in a mutant population by TILLING or separated population by genetic maps, the gene can be introgressed into breeding lines lacking that gene through crosses by the help of visible, biochemical, or molecular markers, i.e., molecular marker-assisted selection (MAS). 


\section{Conclusions}

Based on LD50, here, we inferred the optimal EMS treatment conditions that will benefit future mutagenic research in peanut. Further, the effects of EMS treatment on growth, yield, oil, and seed quality were analyzed. Meanwhile, several mutants related to dwarfism, chlorosis, high oil and/or protein content, seed size and testa color were obtained. Our findings highlight the potential of EMS-induced mutant lines of HY22 and YY45; furthermore, the mutant lines selected in this study may be used as germplasm resources and breeding materials in peanut breeding programs.

Supplementary Materials: The following are available online at http://www.mdpi.com/2073-4395/10/5/655/s1. Table S1: LD50 calculation based on the lethal rate with different EMS treatments.

Author Contributions: T.C. did the experiment and wrote the manuscript. L.H., M.W. and Y.H. analyzed the date. R.Z., X.W. and L.W. did a part of experiment. L.Z. gave good suggestions on the manuscript. S.W. and L.Z. revised the manuscript. All authors have read and agreed to the published version of the manuscript.

Funding: This study was supported by the National Key R\&D Program of China (2018YFD1000906), the Key Science and Technology Planning Project of Guangdong Province (2019B020214003), and the Guangdong Technical System of Peanut and Soybean Industry (2019KJ136-05).

Acknowledgments: We are grateful to the personnel of Shandong Academy of Agricultural Science and Guangdong Academy of Agricultural Science for providing the seed of Huayu 22 and Yueyou 45, respectively. We are also grateful to editor and the anonymous reviewers.

Conflicts of Interest: The authors declare no conflict of interest.

\section{References}

1. FAOSTAT. Food and Agriculture Organization of the United Nations. Available online: http://wwwfaoorg/ (accessed on 30 January 2020).

2. Pandey, M.K.; Monyo, E.; Ozias-Akins, P.; Liang, X.; Guimarães, P.; Nigam, S.N.; Upadhyaya, H.D.; Janila, P.; Zhang, X.; Guo, B. Advances in Arachis genomics for peanut improvement. Biotechnol. Adv. 2012, 30, 639-651. [CrossRef] [PubMed]

3. de Carvalho Moretzsohn, M.; Hopkins, M.S.; Mitchell, S.E.; Kresovich, S.; Valls, J.F.M.; Ferreira, M.E. Genetic diversity of peanut (Arachis hypogaea L.) and its wild relatives based on the analysis of hypervariable regions of the genome. BMC Plant Biol. 2004, 4, 11.

4. Asif, A.; Khalil Ansari, M.Y. Generation of mutant lines of Nigella sativa L. by induced mutagenesis for improved seed yield. Ind. Crop. Prod. 2019, 139, 111552. [CrossRef]

5. Menda, N.; Semel, Y.; Peled, D.; Eshed, Y.; Zamir, D. In silico screening of a saturated mutation library of tomato. Plant J. 2004, 38, 861-872. [CrossRef] [PubMed]

6. Galpaz, N.; Burger, Y.; Lavee, T.; Tzuri, G.; Sherman, A.; Melamed, T.; Eshed, R.; Meir, A.; Portnoy, V.; Bar, E. Genetic and chemical characterization of an EMS induced mutation in Cucumis melo CRTISO gene. Arch. Biochem. Biophys. 2013, 539, 117-125. [CrossRef] [PubMed]

7. Tsuda, M.; Kaga, A.; Anai, T.; Shimizu, T.; Sayama, T.; Takagi, K.; Machita, K.; Watanabe, S.; Nishimura, M.; Yamada, N. Construction of a high-density mutant library in soybean and development of a mutant retrieval method using amplicon sequencing. BMC Genom. 2015, 16, 1014. [CrossRef]

8. Henry, I.M.; Nagalakshmi, U.; Lieberman, M.C.; Ngo, K.J.; Krasileva, K.V.; Vasquez-Gross, H.; Akhunova, A.; Akhunov, E.; Dubcovsky, J.; Tai, T.H. Efficient genome-wide detection and cataloging of EMS-induced mutations using exome capture and next-generation sequencing. Plant Cell 2014, 26, 1382-1397. [CrossRef]

9. Branch, W.D. Variability among advanced gamma-irradiation induced large-seeded mutant breeding lines in the 'Georgia Browne' peanut cultivar. Plant Breed. 2002, 121, 275-277. [CrossRef]

10. Nadaf, H.; Kaveri, S.; Madhusudan, K.; Motagi, B. Induced genetic variability for yield and yield components in peanut (Arachis hypogaea L.). In Induced Plant Mutations in the Genomics Era; FAO: Rome, Italy, 2009; pp. 346-348.

11. Wang, J.; Qiao, L.; Zhao, L.; Wang, P.; Guo, B.; Liu, L.; Sui, J. Performance of peanut mutants and their offspring generated from mixed high-energy particle field radiation and tissue culture. Genet. Mol. Res. 2015, 14, 10837-10848. [CrossRef] 
12. Bera, S.K.; Kamdar, J.H.; Kasundra, S.V.; Dash, P.; Maurya, A.K.; Jasani, M.D.; Chandrashekar, A.B.; Manivannan, N.; Vasanthi, R.P.; Dobariya, K.L.; et al. Improving oil quality by altering levels of fatty acids through marker-assisted selection of ahfad2 alleles in peanut (Arachis hypogaea L.). Euphytica 2018, 214, 162. [CrossRef]

13. Mondal, S.; Badigannavar, A.M.; D'Souza, S.F. Induced variability for fatty acid profile and molecular characterization of high oleate mutant in cultivated groundnut (Arachis hypogaea L.). Plant Breed. 2011, 130, 242-247. [CrossRef]

14. Patel, M.; Jung, S.; Moore, K.; Powell, G.; Ainsworth, C.; Abbott, A. High-oleate peanut mutants result from a MITE insertion into the FAD2 gene. Theor. Appl. Genet. 2004, 108, 1492-1502. [CrossRef] [PubMed]

15. Tang, Y.; Wang, X.; Wu, Q.; Fang, C.; Guan, S.; Yang, W.; Wang, C.T.; Wang, P. Identification of differentially expressed genes from developing seeds of a normal oil peanut cultivar and its high oil EMS mutant. Res. Crop. 2013, 14, 511-516.

16. Wan, L.; Li, B.; Pandey, M.K.; Wu, Y.; Lei, Y.; Yan, L.; Dai, X.; Jiang, H.; Zhang, J.; Wei, G. Transcriptome analysis of a new peanut seed coat mutant for the physiological regulatory mechanism involved in seed coat cracking and pigmentation. Front. Plant Sci. 2016, 7, 1491. [CrossRef]

17. Alberte, R.S.; Hesketh, J.D.; Kirby, J.S. Comparisons of photosynthetic activity and lamellar characteristics of virescent and normal green peanut leaves. Z. Für Pflanzenphysiol. 1976, 77, 152-159. [CrossRef]

18. Sui, J.; Jiang, D.; Zhang, D.; Song, X.; Wang, J.; Zhao, M.; Qiao, L. The salinity responsive mechanism of a hydroxyproline-tolerant mutant of peanut based on digital gene expression profiling analysis. PLOS ONE 2016, 11, e0162556. [CrossRef]

19. Gowda, M.; Bhat, R.; Motagi, B.; Sujay, V.; Kumari, V.; Sujatha, B. Association of high-frequency origin of late leaf spot resistant mutants with AhMITE1 transposition in peanut. Plant Breed. 2010, 129, 567-569.

20. Wan, L.; Li, B.; Lei, Y.; Yan, L.; Ren, X.; Chen, Y.; Dai, X.; Jiang, H.; Zhang, J.; Guo, W. Mutant transcriptome sequencing provides insights into pod development in peanut (Arachis hypogaea L.). Front. Plant Sci. 2017, 8 , 1900. [CrossRef]

21. Maluszynski, M.; Szarejko, I.; Barriga, P.; Balcerzyk, A. Heterosis in crop mutant crosses and production of high yielding lines using doubled haploid systems. Euphytica 2001, 120, 387-398. [CrossRef]

22. Greene, E.A.; Codomo, C.A.; Taylor, N.E.; Henikoff, J.G.; Till, B.J.; Reynolds, S.H.; Enns, L.C.; Burtner, C.; Johnson, J.E.; Odden, A.R. Spectrum of chemically induced mutations from a large-scale reverse-genetic screen in Arabidopsis. Genetics 2003, 164, 731-740.

23. Till, B.J.; Cooper, J.; Tai, T.H.; Colowit, P.; Greene, E.A.; Henikoff, S.; Comai, L. Discovery of chemically induced mutations in rice by TILLING. BMC Plant Biol. 2007, 7, 19. [CrossRef] [PubMed]

24. Sevanthi, A.; Kandwal, P.; Kale, P.B.; Prakash, C.; Ramkumar, M.; Yadav, N.; Mahato, A.K.; Sureshkumar, V.; Behera, M.; Deshmukh, R.K. Whole genome characterization of a few EMS-induced mutants of upland rice variety Nagina 22 reveals a staggeringly high frequency of SNPs which show high phenotypic plasticity towards the wild-type. Front. Plant Sci. 2018, 9, 1179. [CrossRef]

25. Roychowdhury, R.; Tah, J. Genetic variability study for yield and associated quantitative characters in mutant genotypes of Dianthus caryophyllus L. Int. J. Biosci. 2011, 1, 38-44.

26. Kodym, A.; Afza, R. Physical and chemical mutagenesis. In Plant Functional Genomics; Springer: Berlin/Heidelberg, Germany, 2003; pp. 189-203.

27. Zheng, Y.; Zheng, Y.; Wu, Z.; Sun, X.; Wang, C. Study on physiological characteristics and supporting techniques of Huayu 22 peanut. Asian Agric. Res. 2015, 7, 74-82.

28. Li, S.; Liang, X.; Zhou, G. Breeding of a new peanut variety Yueyou 45. Guangdong Agric. Sci. 2010, 11, 19-20.

29. Arisha, M.H.; Shah, S.N.; Gong, Z.; Jing, H.; Li, C.; Zhang, H. Ethyl methane sulfonate induced mutations in M2 generation and physiological variations in M1 generation of peppers (Capsicum annuum L.). Front. Plant Sci. 2015, 6, 399. [CrossRef]

30. Wang, L.; Zhang, B.; Li, J.; Yang, X.; Ren, Z. Ethyl methanesulfonate (EMS)-mediated mutagenesis of cucumber (Cucumis sativus L.). Agric. Sci. 2014, 2014, 48085.

31. Weng, Y.; Shi, A.; Ravelombola, W.S.; Yang, W.; Qin, J.; Motes, D.; Moseley, D.O.; Chen, P. A rapid method for measuring seed protein content in cowpea (Vigna unguiculata (L.) Walp). Am. J. Plant Sci. 2017, 8, 2387. [CrossRef]

32. Arisha, M.; Liang, B.; Shah, S.M.; Gong, Z.; Li, D. Kill curve analysis and response of first generation Capsicum annuum L. B12 cultivar to ethyl methane sulfonate. Genet. Mol. Res. 2014, 13, 10049-10061. [CrossRef] 
33. Shah, S.; Gong, Z.; Arisha, M.; Khan, A.; Tian, S. Effect of ethyl methyl sulfonate concentration and different treatment conditions on germination and seedling growth of the cucumber cultivar Chinese long (9930). Genet. Mol. Res. 2015, 14, 2440-2449. [CrossRef]

34. Gnanamurthy, S.; Dhanavel, D. Effect of EMS on induced morphological mutants and chromosomal variation in Cowpea (Vigna unguiculata (L.) Walp). Int. Lett. Nat. Sci. 2014, 17, 33-43. [CrossRef]

35. Kumar, A.; Kumar, V.; Lal, S.K.; Jolly, M.; Sachdev, A. Influence of gamma rays and ethyl methane sulphonate (EMS) on the levels of phytic acid, raffinose family oligosaccharides and antioxidants in soybean seeds of different genotypes. J. Plant Biochem. Biotechnol. 2015, 24, 204-209. [CrossRef]

36. Ali, H.; Shah, T.M.; Iqbal, N.; Atta, B.M.; Haq, M.A. Mutagenic induction of double-podding trait in different genotypes of chickpea and their characterization by STMS marker. Plant Breed. 2010, 129, 116-119. [CrossRef]

37. Devi, A.S.; Mullainathan, L. Physical and chemical mutagenesis for improvement of chilli (Capsicum annuum L.). World Appl. Sci. J. 2011, 15, 108-113.

38. Borovsky, Y.; Tadmor, Y.; Bar, E.; Meir, A.; Lewinsohn, E.; Paran, I. Induced mutation in $\beta$-CAROTENE HYDROXYLASE results in accumulation of $\beta$-carotene and conversion of red to orange color in pepper fruit. Theor. Appl. Genet. 2013, 126, 557-565. [CrossRef]

39. Kumar, A.P.; Boualem, A.; Bhattacharya, A.; Parikh, S.; Desai, N.; Zambelli, A.; Leon, A.; Chatterjee, M.; Bendahmane, A. SMART-sunflower mutant population and reverse genetic tool for crop improvement. BMC Plant Biol. 2013, 13, 38. [CrossRef]

40. Khan, S.; Goyal, S. Improvement of mungbean varieties through induced mutations. Afr. J. Plant Sci. 2009, 3, 174-180.

41. Wang, T.L.; Uauy, C.; Robson, F.; Till, B. TILLING in extremis. Plant Biotechnol. J. 2012, 10, 761-772. [CrossRef]

42. Uauy, C.; Wulff, B.B.; Dubcovsky, J. Combining traditional mutagenesis with new high-throughput sequencing and genome editing to reveal hidden variation in polyploid wheat. Annu. Rev. Genet. 2017, 51, 435-454. [CrossRef]

43. Bertioli, D.J.; Jenkins, J.; Clevenger, J.; Dudchenko, O.; Gao, D.; Seijo, G.; Leal-Bertioli, S.C.; Ren, L.; Farmer, A.D.; Pandey, M.K. The genome sequence of segmental allotetraploid peanut Arachis hypogaea. Nat. Genet. 2019, 51, 877-884. [CrossRef]

44. Shirasawa, K.; Hirakawa, H.; Nunome, T.; Tabata, S.; Isobe, S. Genome-wide survey of artificial mutations induced by ethyl methanesulfonate and gamma rays in tomato. Plant Biotechnol. J. 2016, 14, 51-60. [CrossRef] [PubMed]

45. McCallum, C.M.; Comai, L.; Greene, E.A.; Henikoff, S. Targeted screening for induced mutations. Nat. Biotechnol. 2000, 18, 455-457. [CrossRef] [PubMed]

46. Krasileva, K.V.; Vasquez-Gross, H.A.; Howell, T.; Bailey, P.; Paraiso, F.; Clissold, L.; Simmonds, J.; Ramirez-Gonzalez, R.H.; Wang, X.; Borrill, P. Uncovering hidden variation in polyploid wheat. Proc. Natl. Acad. Sci. USA 2017, 114, E913-E921. [CrossRef] [PubMed]

47. Winfield, M.O.; Wilkinson, P.A.; Allen, A.M.; Barker, G.L.; Coghill, J.A.; Burridge, A.; Hall, A.; Brenchley, R.C.; D'Amore, R.; Hall, N. Targeted re-sequencing of the allohexaploid wheat exome. Plant Biotechnol. J. 2012, 10, 733-742. [CrossRef] [PubMed]

48. King, R.; Bird, N.; Ramirez-Gonzalez, R.; Coghill, J.A.; Patil, A.; Hassani-Pak, K.; Uauy, C.; Phillips, A.L. Mutation scanning in wheat by exon capture and next-generation sequencing. PLoS ONE 2015, 10, e0137549. [CrossRef]

49. Ashikari, M.; Wu, J.; Yano, M.; Sasaki, T.; Yoshimura, A. Rice gibberellin-insensitive dwarf mutant gene Dwarf 1 encodes the $\alpha$-subunit of GTP-binding protein. Proc. Natl. Acad. Sci. USA 1999, 96, 10284-10289. [CrossRef]

50. Ueguchi-Tanaka, M.; Fujisawa, Y.; Kobayashi, M.; Ashikari, M.; Iwasaki, Y.; Kitano, H.; Matsuoka, M. Rice dwarf mutant $d 1$, which is defective in the $\alpha$ subunit of the heterotrimeric $G$ protein, affects gibberellin signal transduction. Proc. Natl. Acad. Sci. USA 2000, 97, 11638-11643. [CrossRef]

51. Liu, C.; Wang, J.; Huang, T.; Wang, F.; Yuan, F.; Cheng, X.; Zhang, Y.; Shi, S.; Wu, J.; Liu, K. A missense mutation in the VHYNP motif of a DELLA protein causes a semi-dwarf mutant phenotype in Brassica napus. Theor. Appl. Genet. 2010, 121, 249-258. [CrossRef]

52. Sazuka, T.; Kamiya, N.; Nishimura, T.; Ohmae, K.; Sato, Y.; Imamura, K.; Nagato, Y.; Koshiba, T.; Nagamura, Y.; Ashikari, M. A rice tryptophan deficient dwarf mutant, $t d d 1$, contains a reduced level of indole acetic acid and develops abnormal flowers and organless embryos. Plant J. 2009, 60, 227-241. [CrossRef]

53. Bishop, G.J. Brassinosteroid mutants of crops. J. Plant Growth Regul. 2003, 22, 325-335. [CrossRef]

54. Kwon, M.; Choe, S. Brassinosteroid biosynthesis anddwarf mutants. J. Plant Biol. 2005, 48, 1. [CrossRef] 
55. Bennett, T.; Leyser, O. Strigolactone signalling: Standing on the shoulders of DWARFs. Curr. Opin. Plant Biol. 2014, 22, 7-13. [CrossRef] [PubMed]

56. Tanaka, N.; Matsuoka, M.; Kitano, H.; Asano, T.; Kaku, H.; Komatsu, S. gid1, a gibberellin-insensitive dwarf mutant, shows altered regulation of probenazole-inducible protein (PBZ1) in response to cold stress and pathogen attack. Plant Cell Environ. 2006, 29, 619-631. [CrossRef] [PubMed]

57. Takahashi, N.; Nakazawa, M.; Shibata, K.; Yokota, T.; Ishikawa, A.; Suzuki, K.; Kawashima, M.; Ichikawa, T.; Shimada, H.; Matsui, M. shk1-D, a dwarf Arabidopsis mutant caused by activation of the CYP72C1 gene, has altered brassinosteroid levels. Plant J. 2005, 42, 13-22. [CrossRef]

58. Tanabe, S.; Ashikari, M.; Fujioka, S.; Takatsuto, S.; Yoshida, S.; Yano, M.; Yoshimura, A.; Kitano, H.; Matsuoka, M.; Fujisawa, Y. A novel cytochrome P450 is implicated in brassinosteroid biosynthesis via the characterization of a rice dwarf mutant, dwarf11, with reduced seed length. Plant Cell 2005, 17, 776-790. [CrossRef]

59. Jiang, L.; Liu, X.; Xiong, G.; Liu, H.; Chen, F.; Wang, L.; Meng, X.; Liu, G.; Yu, H.; Yuan, Y. DWARF 53 acts as a repressor of strigolactone signalling in rice. Nature 2013, 504, 401-405. [CrossRef]

60. Hooda, M.; Dhillon, R.; Bangarwa, K. Albinism in jojoba (Simmondsia chinensis). Natl. J. Plant Improv. 2004, 1, 69-70.

61. Chen, T.; Zhang, Y.; Zhao, L.; Zhu, Z.; Lin, J.; Zhang, S.; Wang, C. Physiological character and gene mapping in a new green-revertible albino mutant in rice. J. Genet. Genom. 2007, 34, 331-338. [CrossRef]

62. Pawar, N.; Pai, S.; Nimbalkar, M.; Kolar, F.; Dixit, G. Induction of chlorophyll mutants in zingiber officinale roscoe by gamma rays and EMS. Emir. J. Food Agric. 2010, 22, 406-411. [CrossRef]

63. Wang, Z.; Huang, Y.; Miao, Z.; Hu, Z.; Song, X.; Liu, L. Identification and characterization of BGL11 ( $t$ ), a novel gene regulating leaf-color mutation in rice (Oryza sativa L.). Genes Genom. 2013, 35, 491-499. [CrossRef]

64. Mochizuki, N.; Brusslan, J.A.; Larkin, R.; Nagatani, A.; Chory, J. Arabidopsis genomes uncoupled 5 (GUN5) mutant reveals the involvement of $\mathrm{Mg}$-chelatase $\mathrm{H}$ subunit in plastid-to-nucleus signal transduction. Proc. Natl. Acad. Sci. USA 2001, 98, 2053-2058. [CrossRef] [PubMed]

65. Rissler, H.M.; Collakova, E.; DellaPenna, D.; Whelan, J.; Pogson, B.J. Chlorophyll biosynthesis. Expression of a second chl I gene of magnesium chelatase in Arabidopsis supports only limited chlorophyll synthesis. Plant Physiol. 2002, 128, 770-779. [CrossRef] [PubMed]

66. Jensen, P.E.; Petersen, B.L.; Stummann, B.; Henningsen, K.; Willows, R.; Vothknecht, U.; Kannangara, C.; von Wettstein, D. Structural genes for Mg-chelatase subunits in barley: Xantha-f,-g and-h. Mol. Gen. Genet. MGG 1996, 250, 383-394. [PubMed]

67. Zhang, H.; Li, J.; Yoo, J.H.; Yoo, S.C.; Cho, S.H.; Koh, H.J.; Seo, H.S.; Paek, N.C. Rice Chlorina-1 and Chlorina-9 encode ChlD and ChlI subunits of Mg-chelatase, a key enzyme for chlorophyll synthesis and chloroplast development. Plant Mol. Biol. 2006, 62, 325-337. [CrossRef]

68. Jung, K.; Hur, J.; Ryu, C.; Choi, Y.; Chung, Y.; Miyao, A.; Hirochika, H.; An, G. Characterization of a rice chlorophyll-deficient mutant using the T-DNA gene-trap system. Plant Cell Physiol. 2003, 44, 463-472. [CrossRef]

69. Papenbrock, J.; Pfündel, E.; Mock, H.P.; Grimm, B. Decreased and increased expression of the subunit CHL I diminishes $\mathrm{Mg}$ chelatase activity and reduces chlorophyll synthesis in transgenic tobacco plants. Plant J. 2000, 22, 155-164. [CrossRef]

70. Wu, Z.; Zhang, X.; He, B.; Diao, L.; Sheng, S.; Wang, J.; Guo, X.; Su, N.; Wang, L.; Jiang, L.; et al. A chlorophyll-deficient rice mutant with impaired chlorophyllide Esterification in chlorophyll biosynthesis. Plant Physiol. 2007, 145, 29-40. [CrossRef]

71. Zhou, K.; Ren, Y.; Lv, J.; Wang, Y.; Liu, F.; Zhou, F.; Zhao, S.; Chen, S.; Peng, C.; Zhang, X.; et al. Young Leaf Chlorosis 1, a chloroplast-localized gene required for chlorophyll and lutein accumulation during early leaf development in rice. Planta 2013, 237, 279-292. [CrossRef]

72. Chen, Z.; Wang, M.L.; Barkley, N.A.; Pittman, R.N. A simple allele-specific PCR assay for detecting FAD2 alleles in both A and B genomes of the cultivated peanut for high-oleate trait selection. Plant Mol. Biol. Rep. 2010, 28, 542-548. [CrossRef]

73. Wang, Y.; Zhang, X.; Zhao, Y.; Prakash, C.S.; He, G.; Yin, D. Insights into the novel members of the FAD2 gene family involved in high-oleate fluxes in peanut. Genome 2015, 58, 375-383. [CrossRef]

(C) 2020 by the authors. Licensee MDPI, Basel, Switzerland. This article is an open access article distributed under the terms and conditions of the Creative Commons Attribution (CC BY) license (http://creativecommons.org/licenses/by/4.0/). 